\title{
Highly abundant core taxa in the blow within and across captive bottlenose dolphins provide evidence for a temporally stable airway microbiota
}

\author{
Catharina Vendl ${ }^{* *}$ (D) Tiffanie Nelson ${ }^{2}$, Belinda Ferrari ${ }^{3}$, Torsten Thomas ${ }^{4}$ and Tracey Rogers $^{1}$
}

\begin{abstract}
Background: The analysis of blow microbiota has been proposed as a biomarker for respiratory health analysis in cetaceans. Yet, we lack crucial knowledge on the long-term stability of the blow microbiota and its potential changes during disease. Research in humans and mice have provided evidence that respiratory disease is accompanied by a shift in microbial communities of the airways. We investigate here the stability of the community composition of the blow microbiota for 13 captive bottlenose dolphins over eight months including both sick and healthy individuals. We used barcoded tag sequencing of the bacterial 16S rRNA gene. Four of the dolphins experienced distinct medical conditions and received systemic antimicrobial treatment during the study.

Results: We showed that each dolphin harboured a unique community of zero-radius operational taxonomic units (zOTUs) that was present throughout the entire sampling period ('intra-core'). Although for most dolphins there was significant variation over time, overall the intra-core accounted for an average of $73 \%$ of relative abundance of the blow microbiota. In addition, the dolphins shared between 8 and 66 zOTUs on any of the sampling occasions ('inter-core'), accounting for a relative abundance between 17 and $41 \%$ of any dolphin's airway microbiota. The majority of the intra-core and all of the inter-core zOTUs in this study are commonly found in captive and freeranging dolphins and have previously been reported from several different body sites. While we did not find a clear effect of microbial treatment on blow microbiota, age and sex of the dolphins did have such an effect.

Conclusions: The airways of dolphins were colonized by an individual intra-core 'signature' that varied in abundance relative to more temporary bacteria. We speculate that the intra-core bacteria interact with the immune response of the respiratory tract and support its function. This study provides the first evidence of individual-specific airway microbiota in cetaceans that is stable over eight months.
\end{abstract}

Keywords: Dolphin, Cetacean, Respiratory health, Core microbiota, Antimicrobial treatment

\footnotetext{
* Correspondence: c.vendl@unsw.edu.au

'Evolution and Ecology Research Centre, School of Biological, Earth and

Environmental Sciences, University of New South Wales, Sydney, NSW 2052,

Australia

Full list of author information is available at the end of the article
}

C C The Author(s). 2021 Open Access This article is licensed under a Creative Commons Attribution 4.0 International License, which permits use, sharing, adaptation, distribution and reproduction in any medium or format, as long as you give appropriate credit to the original author(s) and the source, provide a link to the Creative Commons licence, and indicate if changes were made. The images or other third party material in this article are included in the article's Creative Commons licence, unless indicated otherwise in a credit line to the material. If material is not included in the article's Creative Commons licence and your intended use is not permitted by statutory regulation or exceeds the permitted use, you will need to obtain permission directly from the copyright holder. To view a copy of this licence, visit http://creativecommons.org/licenses/by/4.0/ The Creative Commons Public Domain Dedication waiver (http://creativecommons.org/publicdomain/zero/1.0/) applies to the data made available in this article, unless otherwise stated in a credit line to the data. 


\section{Background}

Dolphins harbour rich and diverse bacterial communities in the exhaled breath condensate (blow) that they forcefully expel from their airways through their blowhole when at the sea surface [1-6]. The airway microbiota of dolphins are distinct to those of their other body sites, their surrounding seawater [1, 6], air, their prey (fish and squid) and the hand and nose of their human carers in the case of captive dolphins [2]. The bacterial communities in the airways are unique to each individual dolphin. The changes the microbiota of an individual dolphin undergo over relatively short periods of time (two months) are minor compared to the differences between individuals [4].

The analysis of blow microbiota has been considered a promising tool for the health assessment of cetaceans [4-8]. However, to establish blow microbiota as a viable biomarker, crucial knowledge is still lacking: Is the healthy airway microbiota stable over a period longer than two months? Are certain highly prevalent 'core' taxa present that represent a healthy and stable microbiota? Does the airway microbiota of cetaceans reflect the physiological state and the health of its host?

Research on humans and mice has indicated a correlation between airway microbiota and the physical state of the host. Germ-free mice are more susceptible to respiratory infections than conspecifics that carry microbial communities in their airways [9] highlighting the role of the microbiota in disease protection and prevention. Additionally, de Steenhuijsen Piters et al. [10] and Esposito and Principi [11] suggested the human respiratory microbiota to contribute to health regulation. Nevertheless, the temporal stability of the human airway microbiota is under debate [12]. Dickson and Huffnagle [13] and Venkataraman et al. [14] postulated that the bacterial communities in airways of healthy humans are relatively dynamic and transient with few site-specific taxa. In addition, Charlson et al. [15] did not find any shared (core) bacterial sequences in human airways. The same was observed in mice, as Dickson et al. [16] did not find any bacteria common to all mice in their study despite the mice being genetically identical.

Factors, like microbial immigration, elimination and growth rates, as well as the concentration of bacteria in the air determine the community composition of respiratory microbiota in humans [13]. The majority of bacteria in the human airways derives from the oral cavity and reaches the airways via microaspiration, as digestive and respiratory tract intersect [14, 17-19]. The separation of airways and digestive tract in cetaceans [20-22] makes an overlap of microbiota from these two body regions unlikely. And indeed, Bik et al. [1] showed that the blow microbiota in dolphins are very different from those in the oral cavity. The blow microbiota might therefore be a better bacterial representation of the airways in cetaceans than the airway microbiota in humans. On the other hand, due to their marine lifestyle cetaceans developed a more forceful breathing mechanism than humans, as they exhale up to $90 \%$ of their lung volume in one breath [23-25] compared to only $50 \%$ in a physically active human [26, 27]. This might cause a higher turnover rate of bacteria in cetacean airways, potentially making them even more transient than in humans.

A state of disease or even a slight change of immunological capacity of the host $[16,19]$ can change the diversity and overall microbial composition in the airways $[28,29]$. Yet, very little is known about the specific functions airway bacteria may play and how they interact with their host [30]. Furthermore, systemic antibiotic treatment alters [31-33] and suppresses airway microbiota [16] and potentially disturbs the relationship between microbiota and host [34]. Shade and Handelsman [35], Hernandez et al. [36] and Apprill et al. [7] hypothesized that highly prevalent and abundant bacterial species, defined as the core, represent a stable and healthy microbial community as these bacteria interact and benefit the immune system of the host.

Here, to test the temporal stability of dolphin airway microbiota, we characterise the blow microbiota of 13 captive bottlenose dolphins sampled at monthly to bimonthly intervals over an eight-month period. We examine the core bacteria within and across dolphins, as well as the influence of environmental factors, the impact of disease and consequential systemic antimicrobial treatment. We hypothesize that the airways of each dolphin harbour a unique bacterial community throughout the sampling period that maintains a certain level of temporal stability as expressed in a certain number and relative abundance of core bacteria. Furthermore, we predict a significant influence of the antimicrobial treatment and potentially of the compromised health on the microbial blow communities of the dolphins. We seek to contribute new knowledge about the blow microbiota in dolphins to facilitate non-invasive respiratory health assessment in cetaceans in the future.

\section{Results \\ Sample collection}

The dolphin trainers of Sea World Marine Park Gold Coast, Australia, collected samples of exhaled breath condensate ('blow') of 13 captive bottlenose dolphins (Tursiops truncatus) over a period of eight months from April to December 2017. Table 1 presents the sampling schedule listing a total of 86 blow samples, while Table 2 provides additional information on the dolphins, including sex, age and the pool system the animals were kept in. The date of birth was unknown for three dolphins, as 
Table 1 Sample collection dates

\begin{tabular}{|c|c|c|c|c|c|c|c|c|c|c|c|c|c|c|}
\hline Date & Week & Coen & Evie & Kiama & Moki & $R B$ & Scooter & Sirius & Squeak & Starbuck & Stella & Gemma & Howie & Nudgee \\
\hline $05 / 04 / 2017$ & 2 & $\mathrm{x}$ & $\mathrm{x}$ & - & $\mathrm{x}$ & $x$ & $\mathrm{x}$ & $\mathrm{x}$ & $\mathrm{x}$ & $\mathrm{x}$ & $\mathrm{x}$ & & $\mathrm{x}$ & $\mathrm{x}$ \\
\hline $12 / 04 / 2017$ & 3 & & & & & & & & & & & $\mathrm{x}$ & & \\
\hline 03/05/2017 & 6 & $\mathrm{x}$ & $x$ & $\mathrm{x}$ & $\mathrm{x}$ & $\mathrm{x}$ & $x$ & $x$ & $\mathrm{x}$ & $x$ & $\mathrm{x}$ & & $x$ & $\mathrm{x}$ \\
\hline $24 / 05 / 2017$ & 9 & & & & & & & & & & & & $x$ & \\
\hline 07/06/2017 & 11 & $\mathrm{x}$ & $\mathrm{x}$ & $\mathrm{x}$ & $x$ & $\mathrm{x}$ & $\mathrm{x}$ & $\mathrm{x}$ & $\mathrm{x}$ & $x$ & $\mathrm{x}$ & & & \\
\hline $14 / 06 / 2017$ & 12 & & & & & & & & & & & & $\mathrm{x}$ & $\mathrm{x}$ \\
\hline $21 / 06 / 2017$ & 13 & & & & & & & & & & $\mathrm{x}$ & & $\mathrm{x}$ & $\mathrm{x}$ \\
\hline $05 / 07 / 2017$ & 15 & & & & & & & & & & $\mathrm{x}$ & & & \\
\hline $12 / 07 / 2017$ & 16 & & & & & & & & & & $x$ & & $x$ & \\
\hline $19 / 07 / 2017$ & 17 & & & & & & & & & & & & & \\
\hline $02 / 08 / 2017$ & 19 & $x$ & $x$ & $\mathrm{x}$ & $\mathrm{x}$ & $\mathrm{x}$ & $\mathrm{x}$ & $\mathrm{x}$ & $\mathrm{x}$ & $\mathrm{x}$ & $\mathrm{x}$ & & $\mathrm{x}$ & \\
\hline $09 / 08 / 2017$ & 20 & & & & & & & & & & & $x$ & & $x$ \\
\hline $16 / 08 / 2017$ & 21 & & & & & & & & & & & & & $x$ \\
\hline 06/09/2017 & 24 & & & & & & & & & & $x$ & & & - \\
\hline 13/09/2017 & 25 & & & & & & & & & & & $x$ & & \\
\hline 04/10/2017 & 28 & $x$ & $x$ & $x$ & $x$ & $x$ & $x$ & $\mathrm{x}$ & $x$ & $x$ & - & $x$ & $x$ & $x$ \\
\hline $06 / 12 / 2017$ & 37 & - & $\mathrm{x}$ & $\mathrm{x}$ & $\mathrm{x}$ & $\mathrm{x}$ & - & $\mathrm{x}$ & - & $\mathrm{x}$ & $\mathrm{x}$ & $\mathrm{x}$ & - & $\mathrm{x}$ \\
\hline $\begin{array}{c}\text { Total number of } \\
\text { samples }\end{array}$ & & 5 & 6 & 5 & 6 & 6 & 5 & 6 & 5 & 6 & 9 & 5 & 9 & 8 \\
\hline
\end{tabular}

'X'indicates that a blow samples was collected and included in the data analysis. '-indicates that a blow sample was collected, but was discarded due to its number of reads being below 6000. A vertical bold line between the columns of 'Starbuck'and 'Stella'indicates the separation between healthy/ untreated dolphins to the left from the treated dolphins to the right. The time period of antimicrobial treatment in 'Stella', 'Gemma', 'Howie'and 'Nudgee'is indicated by the bold horizontal cell borders and the shaded cells in the associated columns

they were rescued from the wild. Nine out of the 13 dolphins were in good health conditions throughout the sampling period. Four dolphins ('Gemma', 'Howie', 'Nudgee', 'Stella') suffered from a medical condition that required antimicrobial treatment at least once while sampling was performed (Table 2). Table 3 includes their medical condition as well as type and date of antimicrobial treatment. For the nine healthy dolphins, six blow samples each, collected in weeks $2,6,11,19,28$ and 37 , were included into the data analysis (Table 1). For those dolphins that received antimicrobial treatment, we applied a more frequent sampling schedule to be able to closely monitor potential changes of their blow microbiota in response to the treatment (Table 1). Gaps in the extended sampling schedule of the sick dolphins were due to logistical issues at Sea World. Each sampling event was accompanied by one water sample per pool system. Sea World had three large dolphin-holding pool systems ('Dolphin Bay', 'Dolphin Beach', 'Endeavour') and a separate quarantine pool ('QVC') (Fig. 1).

\section{Dataset overview}

In 86 dolphin blow and 28 pool water samples we detected a total of 4,101,122 raw $16 \mathrm{~S}$ rRNA gene sequences, which were clustered into 2175 zero-distance operational taxonomic units (zOTUs). We removed 23 zOTU as they had an overall relative abundance of less than $0.0001 \%$. We deleted five dolphin blow samples from the dataset, as these samples did not meet the set cut-off score of a minimum of 6000 reads (Table 1).

Table 2 Sex, age, pool system the dolphins were kept in and antimicrobial (AB) treatment ( $Y=Y e s, N=N o)$

\begin{tabular}{llllll}
\hline Dolphin ID & Sex & Year of birth & Age level & Pool system & AB treatment \\
\hline Coen & M & 1995 & 2 & Dolphin Beach/ Dolphin Bay & $\mathrm{N}$ \\
Evie & $\mathrm{F}$ & 2008 & 1 & Dolphin Beach & $\mathrm{N}$ \\
Gemma & $\mathrm{F}$ & 1988 & 3 & Dolphin Beach & $\mathrm{Y}$ \\
Howie & $\mathrm{M}$ & unknown & unknown & Endeavour & $\mathrm{Y}$ \\
Kiama & $\mathrm{M}$ & 2003 & 2 & Dolphin Beach & $\mathrm{N}$ \\
Moki & $\mathrm{F}$ & unknown & unknown & Dolphin Beach & $\mathrm{N}$ \\
Nudgee & $\mathrm{M}$ & unknown & unknown & Endeadvour/QVC & $\mathrm{Y}$ \\
RB & $\mathrm{M}$ & 1990 & 3 & Dolphin Bay & $\mathrm{N}$ \\
Scooter & $\mathrm{F}$ & 1983 & 4 & Dolphin Bay & $\mathrm{N}$ \\
Sirius & $\mathrm{M}$ & 1979 & 4 & Dolphin Beach & $\mathrm{N}$ \\
Squeak & $\mathrm{F}$ & 1979 & 4 & Dolphin Beach & $\mathrm{N}$ \\
Starbuck & $\mathrm{M}$ & 1998 & 2 & Dolphin Beach/ Dolphin Bay & $\mathrm{N}$ \\
Stella & $\mathrm{F}$ & 2013 & 1 & Dolphin Beach & $\mathrm{Y}$ \\
\hline
\end{tabular}

Ten dolphins stayed in the same pool for the entire sampling period. Three dolphins were moved between two pools at least once. We assigned four different age levels: $1: 0-10$ years, $2: 11-20$ years, 3: $21-30$ years, $4: 31-40$ years 
Table 3 Cause, type, date and period of antimicrobial (AB) treatment of four dolphins

\begin{tabular}{lllll}
\hline Dolphin ID & Cause of AB treatment & AB medication & AB dosage & Period of treatment \\
\hline Gemma & Aborted calf, prevention of infection & Amoxycillin & Oral administration, 2500 mg, twice a day & 02/05 to 13/06/2017 (6 weeks) \\
Howie & Ocular infection & Doxycycline & Oral administration, 250 mg, twice a day & 30/05 to 07/062017 (7 days) \\
Nudgee & Septic arthritis in shoulder joint & Amoxycillin & Oral administration, 3000 mg, twice a day & 22/06 to 27/07/2017 (5 weeks) \\
& & Gentomicin & Oral administration, 500 mg, once a week & \\
Stella & Inappetence & Amoxycillin & Oral administration, 4000 mg & 05/07/2017 (only once) \\
\hline
\end{tabular}

Furthermore, we deleted 157 zOTUs from the dataset as these were identified as technical contaminants (Table S1, Figs. S1 and S2). The resulting dataset of 81 dolphin blow and 28 pool water samples contained 1991 zOTUs with a mean of 29,168 reads per sample $(\mathrm{sd}=13,578)$. The rarefaction curves of dolphin blow and pool water samples (Figs. S3 and S4) and Good's coverage (Table 4) after filtering showed that the majority of samples was sequenced to near-saturation. After comparing the beta diversity of dolphin blow and pool water microbiota we determined those zOTUs in the dolphin blow that likely originated from pool water and deleted them (Figs. S5 and S6). $1471 \mathrm{zOTUs}$ remained in the dataset as 'true' dolphin blow microbiota.

\section{Alpha diversity parameters differ across individuals but stay stable over time}

After deleting technical and pool water contaminants from the dataset, we calculated four different parameters of alpha diversity (richness, Shannon-Wiener diversity index, Chao1 [38, 39] and ACE [40, 41] species estimators) for each dolphin after rarefying the reads of each sample to the lowest number of reads $(16,578)$ to account for the difference in sampling depth. The alpha diversity parameters averaged to 292 (richness, sd = 108), 4 (ShannonWiener diversity, sd $=0.68), 336$ (Chao1, $\mathrm{sd}=115), 307$ $($ ACE, sd $=111)$ across all 81 dolphin samples. The changes of alpha diversity parameters across time are visualized in Fig. S7 (richness) as well as in Fig. S8 ShannonWiener diversity, S9 (Chao1) and S10 (ACE). These parameters differed significantly between dolphins (richness: $p=0.0015$, diversity: $p=0.0163$, Chao1: $p=0.0008$, ACE: $p=0.0008$ ) and there was no statistical support for changes over the sampling period within the individual dolphins (richness: $p=0.5368$, diversity: $p=0.0938$, Chao1: $p=0.4404$, ACE: $p=0.4998$ ) (Table $4 \&$ S2).

Beta diversity remains fairly stable in individual dolphins, but changes with time

We visualized the beta diversity of microbial communities by creating non-metric multidimensional scaling (nMDS) plots, based on Bray-Curtis dissimilarity and unrarefied data, that showed distinct clustering of dolphin and pool water samples (Fig. 2). To determine if the composition of microbial communities differed between dolphin blow and pool water, we
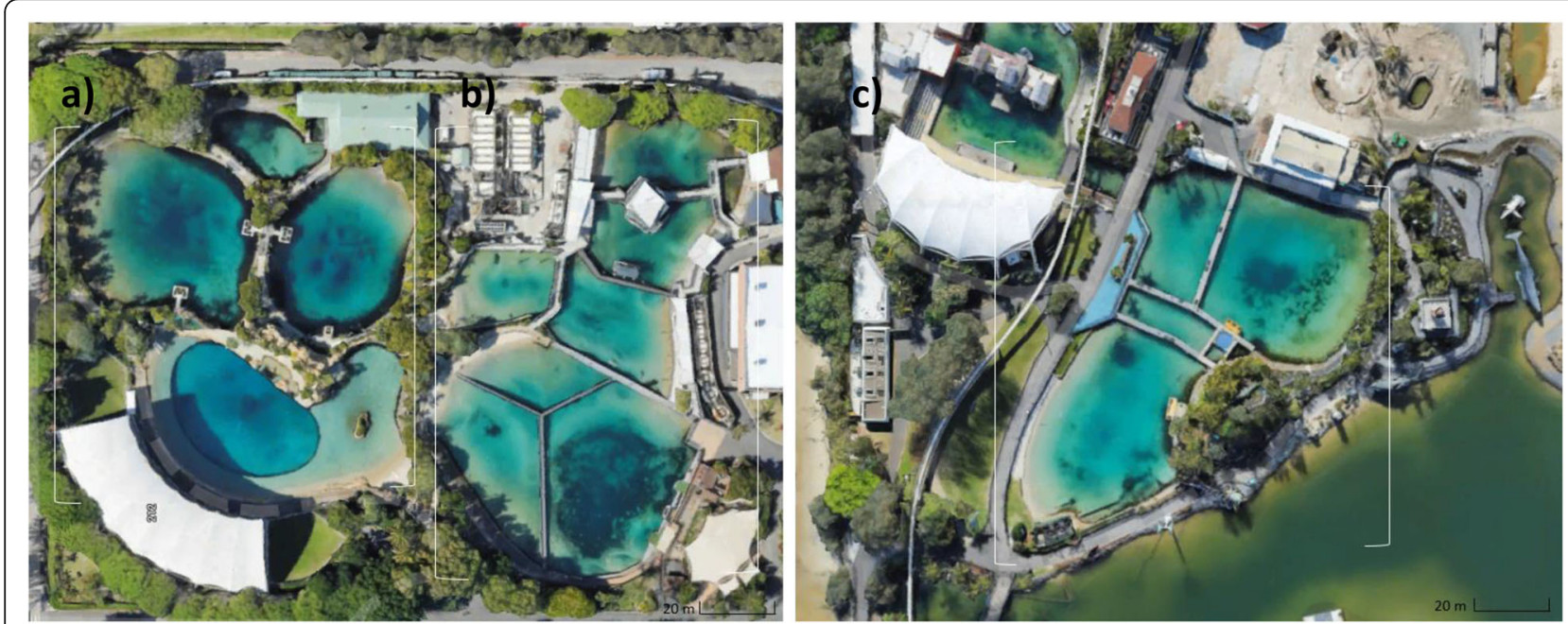

Fig. 1 Aerial view [37] of the three pool systems. a Dolphin Beach, b Dolphin Bay, c Endeavour) at Sea World where sampled dolphins were kept in. Even when partition gates between 'subpools' were closed, water flow between 'subpools' still was still retained. The image was obtained from Google Maps [37] 
Table 4 Good's coverage and alpha diversity parameters of dolphin blow samples

\begin{tabular}{lllllll}
\hline $\begin{array}{l}\text { Dolphin } \\
\text { ID }\end{array}$ & $\begin{array}{l}\text { Good's coverage, mean } \\
(\mathbf{s d})\end{array}$ & $\begin{array}{l}\text { Richness, mean } \\
(\mathbf{s d})\end{array}$ & $\begin{array}{l}\text { Diversity, mean } \\
(\mathbf{s d})\end{array}$ & $\begin{array}{l}\text { Chao1, mean } \\
\text { (sd) }\end{array}$ & $\begin{array}{l}\text { ACE, mean } \\
\text { (sd) }\end{array}$ & $\begin{array}{l}\text { No of intra-core } \\
\text { zOTUs }\end{array}$ \\
\hline Coen & $99.86(0.05)$ & $311(26)$ & $3.62(0.40)$ & $352(36)$ & $327(29)$ & 217 \\
Evie & $99.79(0.05)$ & $361(75)$ & $4.12(0.68)$ & $417(68)$ & $381(75)$ & 167 \\
Gemma & $99.88(0.07)$ & $205(122)$ & $3.48(0.83)$ & $241(118)$ & $221(122)$ & NA \\
Howie & $99.82(0.07)$ & $405(70)$ & $4.27(0.43)$ & $463(68)$ & $429(71)$ & 309 \\
Kiama & $99.82(0.10)$ & $335(50)$ & $4.04(0.38)$ & $380(64)$ & $352(54)$ & 191 \\
Moki & $99.81(0.11)$ & $282(126)$ & $3.67(0.79)$ & $329(138)$ & $297(131)$ & 42 \\
Nudgee & $99.89(0.04)$ & $198(43)$ & $3.44(0.49)$ & $239(60)$ & $210(48)$ & 115 \\
RB & $99.83(0.04)$ & $315(48)$ & $4.09(0.45)$ & $351(43)$ & $331(46)$ & 180 \\
Scooter & $99.88(0.11)$ & $262(135)$ & $4.15(0.56)$ & $305(145)$ & $275(134)$ & 51 \\
Sirius & $99.92(0.03)$ & $224(100)$ & $3.81(0.75)$ & $259(102)$ & $234(101)$ & 38 \\
Squeak & $99.88(0.06)$ & $270(155)$ & $4.12(0.60)$ & $301(165)$ & $284(156)$ & 87 \\
Starbuck & $99.84(0.03)$ & $391(26)$ & $4.17(0.30)$ & $439(33)$ & $406(26)$ & 306 \\
Stella & $99.88(0.04)$ & $224(99)$ & $3.11(0.87)$ & $273(107)$ & $240(103)$
\end{tabular}

The table shows the average of Good's coverage as well as richness, diversity, Chao1 and ACE species estimators of blow samples per dolphin and number of intra-core zOTUs over a period of five months (weeks $6,11,19,28$ ). Gemma and Stella were not included in the calculation of intra-core zOTUs, as they lacked the according samples (No of core zOTUs: NA)

fitted log-link negative binomial models to each zOTU using mvabund [42], with 'dolphin' or 'pool water' as an explanatory factor, Statistical significance was evaluated with anova.manyglm using pit-trap resampling [43], considering the sum of likelihood ratio statistics compared to an intercept-only model. This showed a significant difference between dolphin blow and pool water (sum-of-LR $=24,980 p=0.001$ ). In a similar way, we tested other factors of interest that potentially impacted the microbial communities. Time was one of those factors that was significantly associated with changes in the microbial communities in the airways of the dolphins and on those of the pool water the dolphins were housed in, as the microbiota changed over the eight months of sample collection (dolphin blow: sum-of-LR $=20,140, p=0.002$; pool water: sum-of-LR $=14,064, p=0.002$ ) (changes in dolphin blow microbiota over time: Fig. S11). In addition, the microbial communities of the blow differed between individual dolphins (sum-of-LR $=40,632$, $p=0.001$ ) (Fig. S12). The heatmap of Fig. 3 shows the distribution and relative abundance of 62 zOTUs that most significantly contributed to the differences across the individual dolphins.

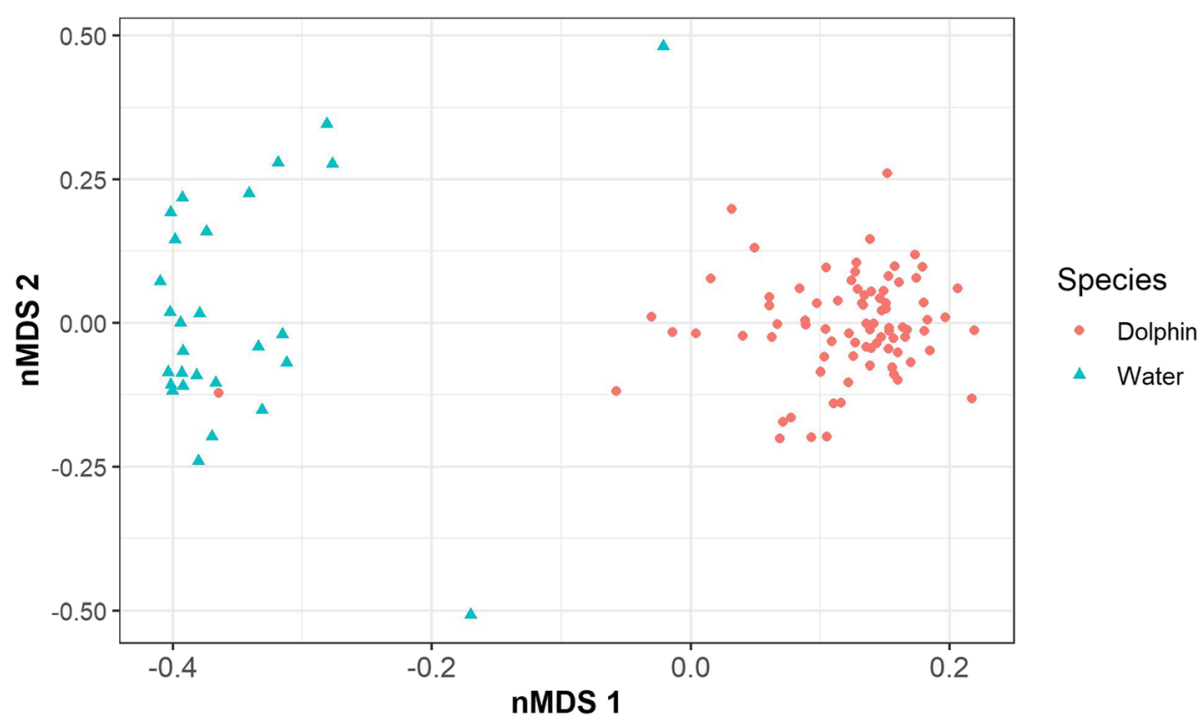

Fig. 2 nMDS of microbiota, based on Bray-Curtis dissimilarity and unrarefied data, found in 81 dolphin blow and 28 pool water samples. A distinct separation between dolphin blow and pool water samples is present 


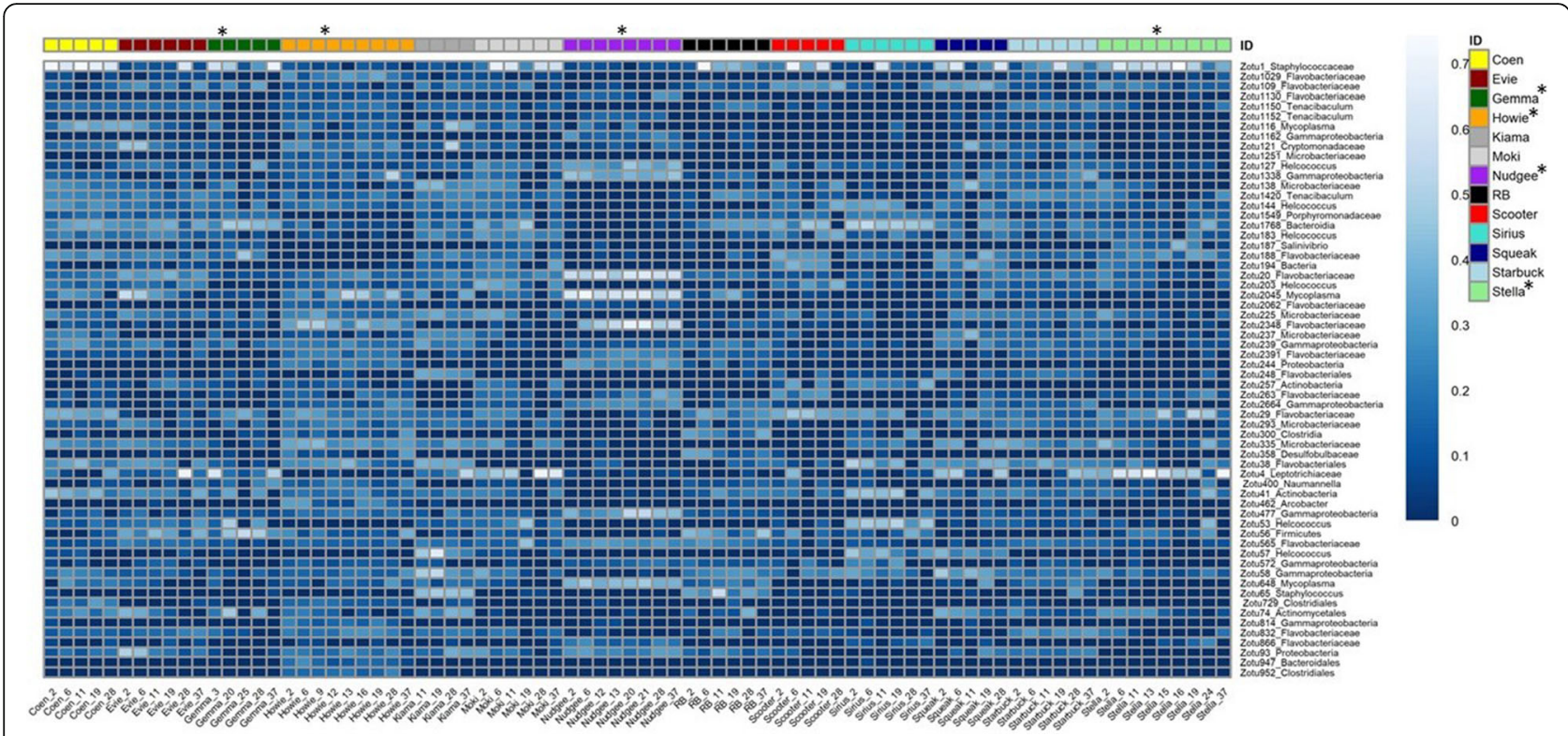

Fig. 3 Heatmap of fourth-root transformed relative abundance of 62 zOTUs identified as significantly different between dolphins. The microbial communities of blow across individual dolphins were shown to be significantly different. The blow samples per dolphin (columns) are listed in chronological order. 'Gemma', 'Howie', 'Nudgee' and 'Stella' were marked with an asterisk to indicate their antimicrobial treatment. The position of the asterisk in the diagram indicates the timing of their treatment

When treated as fixed effects, dolphin ID (12 degrees of freedom) accounted for a deviance of 4470 across all zOTUs, whereas time (15 degrees of freedom) accounted for a deviance of 2591. Expressed relative to the total deviance - as a multivariate version of McFadden's pseudoR2 [44] - dolphin ID accounted for approximately $10 \%$ of the total deviance unexplained by time, while time accounted for about $6 \%$ of the total deviance unexplained by dolphin ID. When treated as random effects, we found that the standard deviation of $\log$ (expected zOTU counts) between dolphins at the same time was about 3.5 times that between time points for the same dolphin.; i.e. zOTU

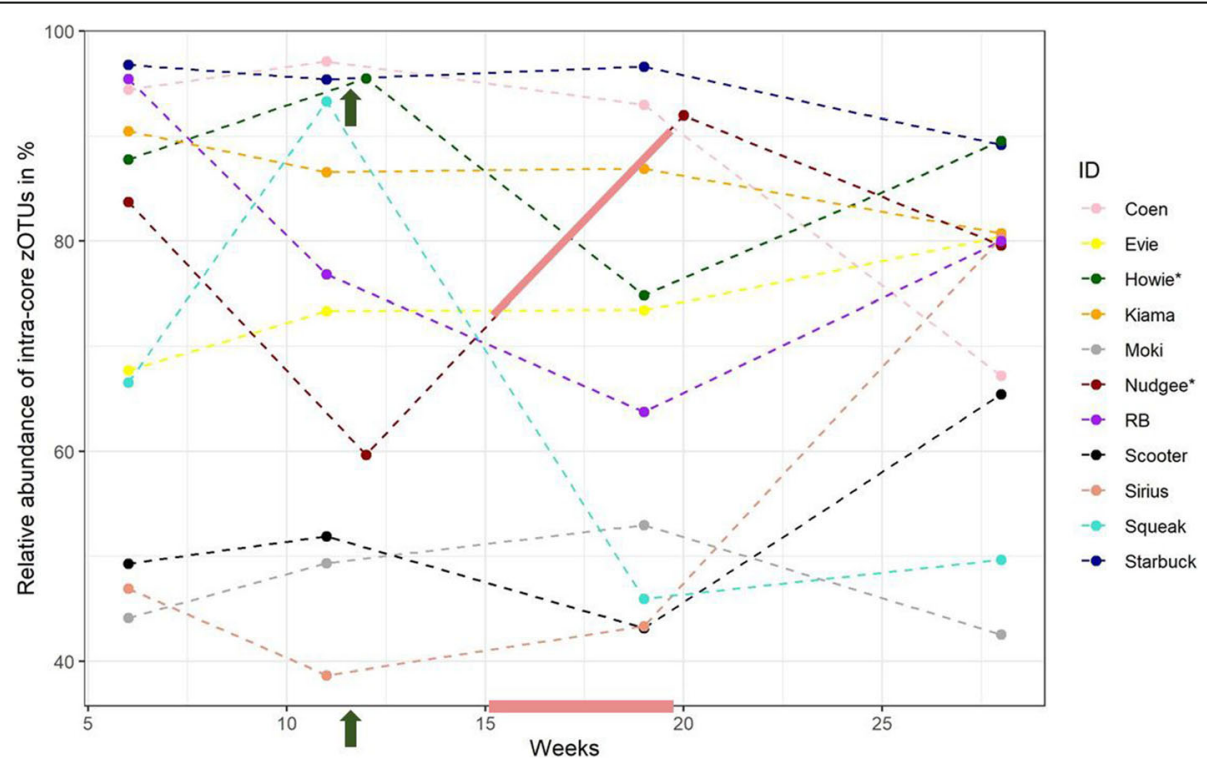

Fig. 4 Total relative abundance of intra-core zOTUs in the blow of 11 bottlenose dolphins at four data points over five months. Only three dolphins showed a relatively stable abundance of their intra-core (variations within 10\% of relative abundance), whereas others displayed a large variation over time. Howie and Nudgee were marked with an asterisk, as they received antimicrobial treatment. The light red bars indicate the period of antimicrobial treatment of Nudgee over several weeks, whereas the green arrows indicate treatment of Howie over a single week 
counts are more variable between dolphins at the same time than they are between time points for the same dolphin. That means that the difference we observed in the blow microbiota between the dolphins were larger than the differences across time. Furthermore, the microbiota of the water differed across the pool systems (sum of LR = 9987, $p=0.001$ ), and there was an effect on the blow microbiota depending on the pool system the dolphins were kept in (sum-of-LR $=1736, p=0.001$ ). The dolphins' sex (sum-of-LR $=2128, p=0.002$ ) (Fig. S13) and age (sum-of-LR $=2762, p=0.001$ ) also had an effect on the blow microbiota (Fig. S14).

\section{Diverse and abundant intra-core in dolphins present over five months}

We determined those zOTUs that persisted in each individual dolphin over time (across weeks 6, 11, 19 \& 28) and labelled them as 'intra-core'. Each dolphin harboured an average of 176 intra-core zOTUs in their blow on each of the four sampling occasions over five months (Table 4). In total, we found 503 intra-core zOTUs. Most intra-core zOTUs were only present in one or two dolphins. Only two intra-core zOTUs were shared by all 11 dolphins (Fig. S15). The relative abundance of the individual intra-core varied over time and among dolphins (Fig. 4), averaging to $73 \%$ relative read abundance across all dolphins and time points. Whereas the relative abundance in some dolphins like 'Starbuck' and 'Kiama' remained fairly stable over time, others showed massive variations. 'Starbuck' harboured the highest relative abundance (94\%) of intra-core zOTUs, averaged over the four time points measured. In contrast, 'Moki's' intra-core only accounted for an average of $47 \%$ of relative read abundance. Most of the intracore zOTUs (449 of the 503) had been reported previously in the blowhole, mouth, rectum or forestomach of bottlenose dolphins as described by Bik et al. (1) (Genbank accession number: e.g., KC260893.1) or Johnson et al. (3) (e.g., FJ959551.1) (Table 5). Those intra-core zOTUs previously found in dolphins accounted for an average of $38 \%$ of each dolphin's total relative read abundance. The taxa with the largest number of intracore zOTUs present were Gammaproteobacteria, Flavobacteriaceae, Bacteroidia and Helcococcus (Table 5). Those dolphin-associated intra-core zOTUs with a relative abundance above $1 \%$ were zOTU1 (6.41\%, ranging from 0 to 29\%, Staphylococcus, CP054831.1), zOTU3 $(4.60 \%$, ranging from 0 to $20 \%$, Flavobacteriaceae, JQ194124.1), zOTU6 (3.21\%, ranging from 0 to $26 \%$, Corynebacteriaceae, JQ216503.1), zOTU9 (3.03\%, ranging from 0 to 19\%, Gammaproteobacteria, JQ193892.1), zOTU2627 (2.98\%, ranging from 0 to 43\%, Flavobacteriaceae, FJ960391.1), zOTU1843 (2.82\%, ranging from 0 to $15 \%$, Flavobacteriaceae, JQ193481.1), zOTU12 (2.21\%, ranging from 0 to $7 \%$, Gammaproteobacteria, JQ209784.1), zOTU8 (2.11\%, ranging from 0 to $15 \%$, Gammaproteobacteria, JQ194121.1), zOTU4 (2.10\%, ranging from 0 to 26\%, Leptotrichiaceae, FJ960123.1), zOTU16 (1.94\%, ranging from 0 to $11 \%$, Flavobacteriaceae, FJ960162.1), zOTU2045 (0.1.78\%, ranging from 0 to 27\%, Mycoplasmataceae, JQ194126.1), zOTU22 (1.48\%, ranging from 0 to $25 \%$, bacteria, JQ193497.1), zOTU20 (1.27\%, ranging from 0 to $15 \%$, Flavobacteriaceae, JQ193429.1), zOTU1768 (1.24\%, ranging from 0 to 86\%, Bacteroidia, JQ194579.1), zOTU120 (1.16\%, ranging from 0 to $10 \%$, Bacteria, JQ214918.1) and zOTU2348 (1.05\%, ranging from 0 to $22 \%$, Flavobacteriaceae, FJ959551.1). The remaining 55 intra-core zOTUs that were not previously detected in dolphins have mostly been reported as present in wastewater (e.g., JX515418.1) or on the skin, the gut or mouth of terrestrial mammals (e.g., EU681994.1) (Table 6). The majority of intra-core bacteria were novel and could therefore not be classified to genus level. Actinobacillus, Arcobacter, Helcococcus and Tenacibaculum were some of the few intra-core taxa that were classified to genus level and that were highly abundant within the core (Tables 5 and 6).

Furthermore, we determined any 'inter-core' zOTUs and their relative abundance. The inter-core was defined as those zOTUs that were present across ten dolphins, randomly selected from our 13 study dolphins, at a specific time point. We picked weeks 2, 6, 11, 19, 28 and 37 as these points in time. Ten dolphins shared an average of $32(\mathrm{sd}=20)$ inter-core zOTUs at any sample collection point in time (weeks 2, 6, 11, 19, 28, 37). The temporal dynamics of the inter-core from week 2 to 37 are visualized in Fig. S20. These inter-core zOTUs accounted for a mean relative read abundance of $25 \%$ $(\mathrm{sd}=9)$ in each dolphin. All 97 inter-core zOTUs detected were also part of the intra-core and were previously collected from the mouth, blowhole or forestomach of bottlenose dolphins [1,3]. About half of the inter-core zOTUs were only present across all ten dolphins at one sampling point (Fig. S16).

\section{Few potential pathogens among intra-core zOTUs}

Within the intra-core of healthy and health-compromised dolphins, 10 zOTUs belonged to genera that comprise pathogenic 'species' linked to infectious disease in marine mammals. These genera included Pseudomonas, Staphylococcus and Mycoplasma (Tables 5 and 6). Venn-Watson $[45,46]$ associated Pseudomonas and Staphylococcus with pneumonia and mortality in bottlenose dolphins, while Mycoplasma is a common causative agent of infectious disease in pinnipeds [47]. We are unable to tell, whether the intra-core, consisting of 449 zOTUs, contained any additional potentially pathogenic genera, as most of the 
Table 5 Taxonomic affiliations of 449 intra-core zOTUs that were previously found in the mouth, forestomach or blowhole of bottlenose dolphins and their Genbank accession number, present across weeks 6, 11, 19 and 28 in 11 dolphins. The majority of listed taxa included more than one intra-core zOTU

No. of core zOTU with the Taxonomic same taxonomic affiliation affiliation

\begin{tabular}{|c|c|c|}
\hline & & (e.g.) \\
\hline 129 & Gammaproteobacteria & JQ209784.1 \\
\hline 119 & Flavobacteriaceae & FJ959551.1 \\
\hline 45 & Bacteria & JQ215599.1 \\
\hline 20 & Helcococcus & FJ959658.1 \\
\hline 11 & Bacteroidia & FJ959660.1 \\
\hline 10 & Clostridiales & JQ214550.1 \\
\hline 9 & SR1_genera_incertae_sedis & JQ216558.1 \\
\hline 8 & Actinobacillus & KC257787.1 \\
\hline 5 & Bacteroidales & FJ959660.1 \\
\hline 5 & Bacteroidetes & JQ215352.1 \\
\hline 4 & Alcaligenaceae & FJ960346.1 \\
\hline 4 & Campylobacterales & FJ959586.1 \\
\hline 4 & Flavobacteriales & JQ194338.1 \\
\hline 4 & Mycoplasma & JQ194022.1 \\
\hline 3 & Desulfobulbaceae & JQ214362.1 \\
\hline 3 & Marinicella & FJ959830.1 \\
\hline 3 & Microbacteriaceae & JQ194103.1 \\
\hline 4 & Oceanospirillales & JQ213884.1 \\
\hline 3 & Phocoenobacter & KC260904.1 \\
\hline 3 & Porphyromonadaceae & JQ209212.1 \\
\hline 2 & Actinomycetales & JQ208827.1 \\
\hline 2 & Cardiobacteriales & FJ960414.1 \\
\hline 2 & Guggenheimella & FJ959658.1 \\
\hline 2 & Firmicutes & JF917274.1 \\
\hline 2 & Lachnospiraceae & JQ214724.1 \\
\hline 2 & Mycoplasmataceae & JQ194022.1 \\
\hline 2 & Peptoniphilaceae & JQ211561.1 \\
\hline 2 & Proteobacteria & FJ959558.1 \\
\hline 2 & Pseudomonadales & JQ194701.1 \\
\hline 2 & Sphingobacteriia & FJ959720.1 \\
\hline 1 & Actinobacteria & JQ216846.1 \\
\hline 1 & Alicyclobacillus & KC259493.1 \\
\hline 1 & Anaerovorax & FJ959595.1 \\
\hline 1 & Betaproteobacteria & FJ959731.1 \\
\hline 1 & Burkholderiales & FJ959744.1 \\
\hline 1 & Corynebacteriaceae & JQ216503.1 \\
\hline 1 & Cryomorphaceae & JQ194623.1 \\
\hline 1 & Deltaproteobacteria & JQ214362.1 \\
\hline 1 & Epsilonproteobacteria & FJ959609.1 \\
\hline 1 & Firmicutes & JQ194061.1 \\
\hline
\end{tabular}

Table 5 Taxonomic affiliations of 449 intra-core zOTUs that were previously found in the mouth, forestomach or blowhole of bottlenose dolphins and their Genbank accession number, present across weeks 6, 11, 19 and 28 in 11 dolphins. The majority of listed taxa included more than one intra-core zOTU (Continued)

\begin{tabular}{lll}
\hline $\begin{array}{l}\text { No. of core zOTU with the } \\
\text { same taxonomic affiliation }\end{array}$ & $\begin{array}{l}\text { Taxonomic } \\
\text { affiliation }\end{array}$ & $\begin{array}{l}\text { Genbank } \\
\text { accession } \\
(\mathbf{e . g} .)\end{array}$ \\
\hline 1 & $\begin{array}{l}\text { Leptotrichiaceae } \\
\text { Microbacteriaceae }\end{array}$ & $\begin{array}{l}\text { FJ960123.1 } \\
\text { LR640309.1 }\end{array}$ \\
1 & Naumannella & KC259559.1 \\
1 & Parcubacteria_genera_ & JQ209049.1 \\
1 & incertae_sedis & \\
1 & Pasteurellaceae & JQ193892.1 \\
1 & Proteobacteria & KM823720.1 \\
1 & Pseudomonas & CP041013.1 \\
1 & Salinivibrio & JQ194108.1 \\
1 & Spirochaetaceae & KC259401.1 \\
1 & Spirochaetes & KC259034.1 \\
1 & Spirochaetia & KC260523.1 \\
1 & Staphylococcaceae & CP054831.1 \\
1 & Staphylococcus & CP054831.1 \\
1 & Sulfurospirillum & JQ215956.1 \\
1 & Treponema & KC260218.1 \\
\hline
\end{tabular}

core members were novel and could therefore not be classified to genus level.

\section{Antimicrobial treatment might have short term effect on airway microbiota}

To test the potential effect of the medical condition and antimicrobial treatment of four dolphins on their microbial communities, we classified the blow samples into four groups: samples from dolphins that were in good physical conditions and therefore didn't receive any antimicrobial treatment were labelled as 'None'. Samples of physiologically compromised and treated dolphins that were collected before the animal was treated received the label 'Before'. Those samples that were collected (within one week) after the animals were treated were called 'Directly_After'and those samples collected at least two weeks after treatment were named 'After'. The blow microbiota of the dolphins with medical conditions (Table 3 ) generally (compared over the entire sampling period) did not differ from those of the healthy dolphins (sum-of-LR $=7607, p=$ 0.121) (Fig. S17). The healthy dolphins' blow bacterial communities were also not significantly different to those of the sick dolphins before ('None'vs. 'Before': sum-of-LR $=11.1, p=0.077$ ), directly after ('None'vs. 
'Directly_After': sum-of-LR $=881.8, p=0.105)$ and after antimicrobial treatment ('None'vs. 'After': sum-of$\mathrm{LR}=20.32, p=0.108)$. In addition, the microbial communities of the sick dolphins did not differ 'before' and 'after' the antimicrobial treatment (sum-of-LR $=2102$, $p=0.166$ ). However, we detected a slight difference between the blow microbiota 'before' and 'directly after' the treatment (sum-of-LR $=1910, p=0.049$ ) (Fig. S18). Interestingly, we also found a significant difference between the samples of the sick dolphins collected 'directly after' and at least two weeks 'after' the application of antibiotics (sum-of-LR $=2545, p=0.016$ ) (Fig. S19).

Two of the dolphins included in this study ('Gemma' and 'Nudgee') were both treated with Amoxycillin twice a day over a period of five to six weeks (Table 3). To test for a potential impact of the Amoxycillin treatment on the airway microbiota of the two dolphins, we firstly compared the samples of 'Gemma' and 'Nudgee' after their treatment with those of the other dolphins that did not receive any antimicrobial treatment during the course of the sample collection. We received a result which was close to significant (sum-of-LR $=1214, p=$ 0.054). Secondly, we compared the samples of 'Gemma' and 'Nudgee' before they were treated with Amoxycillin with those after their treatment. In this case, we did not find evidence of a significant difference (sum-of-LR $=0$, $p=0.999)$.

\section{Discussion}

\section{Dolphins harboured individual-specific 'signature' microbiota (intra-core) in blow}

The dolphins in this study harboured bacterial communities in their blow that changed in their alpha and beta diversity over the sampling period of eight months. However, we found evidence to conclude that individual identity of the dolphins had a higher determining impact on the blow microbiota than the factor of time (Fig. 3 \& S15). Thus, our findings support the short-term results of Lima et al. [4] over a substantially longer time scale. In addition, each dolphin showed a unique intra-core 'signature' (Fig. 4), as the majority of intra-core zOTUs were present in a single or two dolphins (Fig. S13). With an average of $73 \%$ (ranging between 47 to $94 \%$ ) of the relative read abundance, the intra-core zOTUs dominated the blow microbiota of individual dolphins, whereas in humans and mice proof of a communal bacterial core of the airways is still lacking $(15,16)$. Thus, our findings provide evidence that the bacterial communities in dolphin blow are not merely transient. In fact, as much as $38 \%$ of the blow microbiota in our study animals had been reported previously in bottlenose dolphins. We propose that dolphins harbour a relatively stable individual-specific microbiota that colonizes the airways. Nevertheless, we found that the relative read abundance of intra-core zOTUs varied across time in most dolphins, including the healthy animals (Fig. 4). Segal et al. [19] and Dickson et al. [16] demonstrated in humans and mice that changes in the airway microbiota can occur even without any obvious clinical signs. Slight shifts in immune function were found to impact the respiratory microbial communities and they may have been at play here. The strong variation in intra-core zOTUs within individuals highlights that the lung microbiota of dolphins is dynamic and there are likely internal physiological as well as external factors such as temperature [48] involved that impact the bacterial communities on a day-to-day basis.

\section{Dolphins shared significant number of inter-core with conspecifics}

In addition, the dolphins did not only maintain a stable intra-core over time, but also harboured a significant number of inter-core zOTUs that they shared with their conspecifics across pools at certain time points. With a mean of $25 \%$ of relative read abundance, the inter-core in our dolphins was less abundant than that Apprill et al. [7] found in the blow across 26 humpback whales. Yet, Apprill et al. [7] only determined the inter-core at one single time point, whereas we noticed a large variation in relative abundance of inter-core with a range of 17 and $41 \%$ in our dolphins across time (Fig. S20). However, it is interesting to notice that Apprill et al. [7] found the humpback whales to share more than a third of their blow microbiota across two populations (north Atlantic and Pacific Ocean), whereas our study dolphins were kept in the same facility and some even shared the same pool system. This provides additional evidence for the airway microbiota of cetaceans to maintain a certain ratio of stable individual-specific core residents that may be relatively independent of environmental influences.

\section{Impact of antimicrobial treatment was not clearly evident} We did not find clear evidence that the antimicrobial treatment that the dolphins received in this study had a significant impact on their blow microbiota. There was no general difference between the microbial communities of the sick vs. the health dolphins, seen over the entire sampling period. However, within the dolphins that received treatment, we found evidence that the bacterial blow communities were impacted right after the antimicrobial treatment and returned back to 'normal' within two weeks of treatment (Figs. S18 \& S19). We can only speculate that the blow microbiota were indeed briefly impacted by the treatment and returned back to their physiological state soon after (no difference to the blow of healthy, untreated dolphins). It is interesting to notice that the relative read abundance of intra-core zOTUs and its variation over time did not show any 
Table 6 Intra-core zOTUs that were not previously found in bottlenose dolphins, their taxonomic affiliation, source, average relative abundance across dolphins and Genbank accession number, present across weeks 6, 11, 19 and 28 in 11 dolphins

\begin{tabular}{|c|c|c|c|}
\hline zOTU no. & Taxonomic affiliation & Environment of most similar sequences & Genbank accession \\
\hline Zotu0001 & Microbacteriaceae & Human urinary tract & CP054831.1 \\
\hline Zotu0025 & Staphylococcaceae & Human urinary tract & СР054831.1 \\
\hline Zotu0033 & Corynebacteriaceae & Human skin & KU689893.1 \\
\hline Zotu0056 & Firmicutes & Mineral hot springs & JF917274.1 \\
\hline Zotu0065 & Staphylococcus aureus & Human blood & HG795797.1 \\
\hline Zotu0072 & Staphylococcus & Frog skin & HM330254.1 \\
\hline Zotu0079 & Bacteroidetes & California sea lion stomach & KF067368.1 \\
\hline Zotu0138 & Microbacterium esteraromaticum & bioaerosol & MG751356.1 \\
\hline Zotu0141 & Betaproteobacterium & hypersaline lake & MG282144.1 \\
\hline Zotu0149 & Microbacteriaceae & wastewater & GQ062150 \\
\hline Zotu0175 & Leucobacter sp. & soil & GU235593.1 \\
\hline Zotu0180 & Bacteria & seawater & MK129353.1 \\
\hline Zotu0210 & Salinivibrio costicola & Human skin & JN683955.1 \\
\hline Zotu0221 & Gammaproteobacteria & Human skin & JF153221.1 \\
\hline Zotu0223 & Bacteriovoracaceae & seawater & $J \times 294354.1$ \\
\hline Zotu0237 & Microbacteriaceae & cheese rind & LT698608.1 \\
\hline Zotu0259 & Microbacteriaceae & Wastewater treatment system & LR640309.1 \\
\hline Zotu0279 & Clostridia & human skin & JQ205124.1 \\
\hline Zotu0300 & Leucobacter sp. & human skin & FN823848.1 \\
\hline Zotu0313 & Okibacterium sp. & soil & GU235593.1 \\
\hline Zotu0335 & Comamonadaceae & soil & EU681994.1 \\
\hline Zotu0355 & Marine bacteria & Human skin & MG099642.1 \\
\hline Zotu0368 & Vibrio sp. & seawater & MG705679.1 \\
\hline Zotu0377 & Bacteriovoracaceae & marine sediment & GU235593.1 \\
\hline Zotu0385 & Gracilibacteria bacterium oral taxon 873 & wastewater & GU235593.1 \\
\hline Zotu0417 & Prevotella melaninogenica & human oral cavity & MK129353.1 \\
\hline Zotu0420 & Bacteriovoracaceae & human skin & JN713493.1 \\
\hline Zotu0422 & Gammaproteobacteria & seawater & $J Q 380127.2$ \\
\hline Zotu0460 & Vibrio & California sea lion mouth & EU137548.1 \\
\hline Zotu0491 & Marine bacteria & unknown & СР014053.1 \\
\hline Zotu0508 & SR1_genera_incertae_sedis & Seawater & HQ122382.1 \\
\hline Zotu0521 & Vibrio sp. & Dog gut & KF571771.1 \\
\hline Zotu0570 & Microbacterium esteraromaticum & coral & СР032548.1 \\
\hline Zotu0590 & Marine bacteria & bioaerosol & MK506675.1 \\
\hline Zotu0645 & Marine bacteria & seawater & KU689893.1 \\
\hline Zotu0723 & Vibrio sp. & seawater & HG795797.1 \\
\hline Zotu0763 & Gracilibacteria bacterium canine oral taxon 323 & marine sediment & HM330254.1 \\
\hline Zotu0835 & Bacteria & dog's oral cavity & KF067368.1 \\
\hline Zotu0954 & Bacteria & coral & JF087814.1 \\
\hline Zotu0959 & Bacteriovoracaceae & prairie dog flea & MG751356.1 \\
\hline Zotu1083 & Vibrio alginolyticus & Seawater & KU689893.1 \\
\hline Zotu1157 & Escherichia coli & Seawater & MG282144.1 \\
\hline Zotu1214 & Bacteroidetes & human feces & JF087814.1 \\
\hline
\end{tabular}


Table 6 Intra-core zOTUs that were not previously found in bottlenose dolphins, their taxonomic affiliation, source, average relative abundance across dolphins and Genbank accession number, present across weeks 6, 11, 19 and 28 in 11 dolphins (Continued)

\begin{tabular}{llll}
\hline zOTU no. & Taxonomic affiliation & Environment of most similar sequences & Genbank accession \\
\hline Zotu1449 & Marine bacteria & Seawater & GQ062150 \\
Zotu1620 & Methylophaga & Seawater & GU235593.1 \\
Zotu1639 & Marine bacteria & fresh water fish & KF571771.1 \\
Zotu1644 & Tenacibaculum sp. DSM 106434 & Seawater & GU235593.1 \\
Zotu1840 & Staphylococcus & fish skin & MK129353.1 \\
Zotu1968 & Gammaproteobacteria & Human skin & CP054831.1 \\
Zotu2070 & Staphylococcus & frog skin & JN683955.1 \\
Zotu2659 & Corynebacteriaceae & human skin & HM330254.1 \\
\hline
\end{tabular}

obvious changes right after the application of antimicrobial treatment (Fig. 4). When comparing the samples of the two dolphins that were treated with Amoxycillin over several weeks with those of the dolphins that did not receive any treatment, we received an outcome which was just above the significance threshold. Although the statistical result was not clear, it might hint towards an impact of the Amoxycillin treatment on the microbial communities.

\section{Sex, age and social setting of dolphins appeared to impact blow microbiota}

In contrast to Lima et al. [4] and Bik et al. [1], we found an impact of sex and age of the dolphins on their airway microbiota (Figs. S13 \& S14). Furthermore, the pool system the dolphins were kept in also made a significant difference. Although the bacterial communities differed across the pool systems, we assumed that the filtering of dolphin blow samples from the pool water bacteria early on in our analysis would have prevented a large impact from the pool water itself on the airway microbiota of dolphins. Hence, we followed speculations of Bik et al. [1] and hypothesized that dolphins kept in the same pool system inoculate each other's airways with their blow microbiota and therefore contribute to their pool mates' blow community composition. A similar effect has been shown for children whose airway microbiota changed with the number of their social contacts [49] as well as for mice housed in the same cage, known as cageeffect [50].

\section{Conclusions}

We conclude that the airways of dolphins are colonized by resident core bacteria that can differ in abundance in relation to more transient bacteria. Although we did not find a clear correlation between these core bacteria and the health of the dolphins, potentially due to the small sample size of sick dolphins and the variation of their illnesses, we speculate that these individual-specific core bacteria interact with the immune response of the respiratory tract and support its function. To support our assumption, a larger number of dolphins with a consistent respiratory pathophysiology and additional local immune parameters need to be analysed. For now, we confirm the potential of the analysis of blow microbiota as a future biomarker for the physiological state of the airways in cetaceans.

\section{Methods \\ Sample collection}

Sea World Marine Park Gold Coast, Australia, granted us permission to use the blow samples of 13 captive bottlenose dolphins (Tursiops truncatus) for this study. We tested the microbiota in the blow samples for temporal stability over a period of eight months. The dolphins were kept in three separate pool systems and a quarantine pool (Fig. 1). Three of the 13 sampled dolphins were moved between pools at least once (Table 2). The pools the dolphins were kept in were fed by a constant influx of seawater from the adjacent Pacific Ocean. The pool systems (Fig. 1) could be divided into four to six 'subpools' by closing the partition gates. Even when gates between 'subpools' were closed, water flow was retained between the pools. Therefore, a water sample of any of the 'subpools' was representative for the entire pool system.

The dolphins were trained to exhale on command. Sample collection was generally performed on Monday mornings at $9 \mathrm{am}$, as part of a feeding and enrichment session. After blow sample collected for this study was completed, the dolphins remained in the care of Sea World. For each sampling event the trainer held a sterile 'yellow cap' container (Techno Plas Pty Ltd., St Marys, South Australia, Australia) with a maximum volume of $70 \mathrm{ml}$, with its lid removed, upside down about $10 \mathrm{~cm}$ above the dolphin's blowhole. Once the dolphin had exhaled, the trainer screwed the lid back on and stored the sample in an Esky on ice. Each sample contained a volume of approximately $200 \mu \mathrm{l}$. Every time the trainers collected blow samples from the dolphins, they also took 
a sample of the surface water of each pool system as controls. A volume of about $200 \mathrm{ml}$ was collected per water sample using a sterile 'yellow cap' container (Techno Plas Pty Ltd., St Marys, South Australia, Australia). We selected the surface water for sample collection, as this is the layer the dolphins were most likely to inhale small quantities of during their breathing cycle [6]. Samples were transferred from the ice-filled Esky to a $-20^{\circ} \mathrm{C}$ freezer following collection and then shipped to UNSW on dry ice.

\section{DNA extraction and 16S rRNA gene sequencing}

The water samples were filtered through a Sterivex filter unit $(0.22 \mu \mathrm{m}$, EMD Millipore Corporation, Billerica, USA). The liquid of the blow samples was transferred from collection containers into the tubes provided with the FastDNA Spin Kit for Soil (MP Biomedicals, Santa Ana, California, USA). We extracted the nucleic acids from blow and water samples following the manufacturer's protocol (MP Biomedicals, Santa Ana, California, USA). For amplification of the genetic regions (V1 - V3) of the samples' nucleic acids, we followed the protocol in Vendl et al. [51]. We included the following samples as technical controls in the DNA amplification process: two positive PCR controls (PCR reagents plus the genomic DNA of Escherischia coli), seven negative PCR controls (PCR reagents only with sterile water instead of DNA sample) and four blank DNA extractions (reagents for DNA extraction only). We sent the PCR products to the Ramaciotti Centre for Genomics (UNSW Sydney, Australia) where samples were processed for purification, library preparation and paired-end amplicon sequencing $(2 \times 300 \mathrm{bp})$ on the Illumina MiSeq platform.

\section{Sequence data processing}

We performed an initial quality check with FastQC [52], and processed the paired-end reads with USEARCH version 10.240 [53]. We followed the protocol of Vendl et al. [51] for further bioinformatic processing. As in Vendl et al. [51] the reads were clustered into zeroradius operational taxonomic units (zOTUs) with 100\% similarity. The use of zOTUs is therefore a similar approach to the formation of amplicon sequence variants (ASV) [54].

\section{Data analysis}

We removed those zOTUs from the dataset that were shown to be Archaea, chloroplasts or mitochondria. Prevalence-based filtering of potential technical contaminant zOTUs (derived from positive and negative PCR controls and blank DNA extractions) was performed using the $\mathrm{R}$ package decontam ( $\mathrm{v}$ 3.12) [55]. We used zOTU tables as input for both the isContaminant() and isNotContaminant() function. For both functions the following parameters were applied: (method = "prevalence," threshold $=0.5$, normalize $=$ TRUE, detailed $=$ TRUE) as demonstrated in Seferovic [56]. We identified $157 \mathrm{zOTUs}$ that likely originated from technical controls (Table S1, Figs. S1 and S2) and deleted them from the dolphin blow dataset. Figure S2 shows the bimodal division between dolphin zOTUs and technical control zOTUs. Furthermore, after filtering the technical contaminants, we scanned for those zOTUs in the dolphin microbiota that likely derived from pool water. We pooled all 28 water samples collected over the sampling period and compared them to the dolphin zOTUs. To identify water contaminants, we used the same parameters as for the technical contaminants within the $\mathrm{R}$ package decontam. 520 zOTUs were identified as belonging to the pool water samples and were deleted, while 1471 zOTUs remained in the dolphin microbiota. Figure S5 shows the bimodal division between dolphin zOTUs and water control zOTUs.

We created rarefaction curves of the samples using the package phyloseq (v1.24.2) [57]. The rarefaction curves and the related rarefaction analysis tested, if the blow and seawater microbiota were sampled to saturation and therefore well represented the microbial communities they were sampled from. We discarded six dolphin samples, as their number of counts were below 6000 reads (Table 1). We used the R package nlme (v3.1-140) [55] to assess whether the four alpha diversity parameters were associated with the time of sample collection or the individual dolphins [58]. For each parameter of alpha diversity (e.g., richness, Chao1), we fitted linear mixed effects models with a fixed effect of 'Dolphin ID' (individual dolphins) or 'time' (the week sample was collected), depending on which factor the model tested for, random intercepts for 'time' or 'Dolphin ID', and a continuous AR(1) residual structure, and applied a likelihood ratio test to compare models with and without a fixed effect of 'Dolphin ID' or 'time'. To assess the importance of the random intercepts in this model (impact of individual dolphins), we performed a restricted likelihood ratio test using the RLRsim package (v3.1-3) in R [59].

To determine if any of the factors of interest (e.g., dolphin blow vs. pool water, dolphin ID, time, antimicrobial treatment, age, sex) were associated with the composition of the microbial communities tested, we fitted loglink negative binomial models to each zOTU, with the factor(s) in question included as fixed effects using mvabund (v4.0.1) [42], in each case, the log of total sequence counts per sample included as an offset to account for differences in sampling depth. Statistical significance was evaluated with the anova.manyglm function, which uses pit-trap resampling [43], considering the sum-of-likelihood ratio statistics compared to a 
model excluding the factor of interest. This approach to the analysis of microbiota composition with mvabund has been previously described in detail by Vendl et al. [51] (Supplementary materials S3).

As an alternative method of examining the relative contribution of dolphin ID and time to the variation in microbiome composition, we fit a similar log-link negative binomial model using glmmTMB (v1.0.2.1) [60], this time including dolphin ID and time as multivariate random effects across zOTUs. Here, the outcome of main interest was the relative size of the estimated variances of these random effects.

Bacterial beta diversity of pool water and dolphin blow samples, as well as that of some of the other factors in question (e.g., age, sex, dolphin ID) was visualized using the package vegan (v2.5-5) for community ecology analysis [61] .

To ensure comparability of intra-core zOTUs across dolphins, we exclusively considered four samples per dolphin (weeks $6,11,19,28$ ) over five months. We excluded the weeks 2 and 37, as we lacked the samples of several dolphins for these weeks (Table 1). Including those would have resulted in a smaller number of dolphins in the analysis of intra-core, as we wanted to make sure to use the same number of samples (four) per dolphin. We excluded 'Stella' and 'Gemma' from the intracore analysis, as they did not have all required samples over the above-mentioned weeks. Missing samples of 'Howie' and 'Nudgee' were replaced by those obtained a week before or after. 'Howie' and 'Nudgee' were the only two dolphins included in the intra-core analysis that were treated with antibiotics. Statistical analysis of microbial community results was performed using $\mathrm{R}$ statistical software (v3.5.1) (http://cran.r-project.org/).

\section{Supplementary Information}

The online version contains supplementary material available at https://doi. org/10.1186/s12866-020-02076-z.

Additional file 1: Fig. S1. Shows a scatterplot of the technical contaminant ZOTUs of control samples ('TRUE' in green) and dolphins blow zOTUs ('FALSE' in red). The R package decontam determined 157 technical contaminants which were then deleted from the 81 dolphin blow samples. Fig. S2. Shows a histogram of the technical contaminant zOTUs of control samples (bars on the left) and dolphins blow zOTUs (bars on the right). The R package decontam determined 157 technical contaminants which were then deleted from the 81 dolphin blow samples. The figure shows the bimodal division between dolphin zOTUs and technical control zOTUs. Fig. S3. Rarefaction curves of dolphin blow samples. The majority of samples was sampled to saturation. Fig. S4. Rarefaction curves of pool water samples. The majority of samples was sampled to saturation. Fig. S5. Shows a scatterplot of the contaminant zOTUs of pool water samples ('TRUE' in green) and dolphins blow zOTUs ('FALSE' in red). The R package decontam determined 520 water contaminants which were then deleted from the 81 dolphin blow samples. Fig. S6. Shows a histogram of the water contaminant zOTUs of pool water samples (bars on the left) and dolphins blow zOTUs (bars on the right). The $\mathrm{R}$ package decontam determined 520 water contaminants which were then deleted from the 81 dolphin blow samples. The figure shows the bimodal division between dolphin zOTUs and water zOTUs. Fig. S7. Shows the alpha diversity parameter, richness, across 37 weeks of sample collection in the 13 study dolphins. Fig. S8. Shows the alpha diversity parameter, Shannon-Wiener diversity, across 37 weeks of sample collection in the 13 study dolphins. Fig. S9. Shows the alpha diversity parameter, Chao1, across 37 weeks of sample collection in the 13 study dolphins. Fig. S10. Shows the alpha diversity parameter, ACE, across 37 weeks of sample collection in the 13 study dolphins. Fig. S11. nMDS plot based on Bray-Curtis dissimilarity matrix of 81 dolphin blow and 28 pool water samples. A clear distinction between the microbial community composition in dolphin blow and pool water is evident. Fig. S12. nMDS plot based on Bray-Curtis dissimilarity matrix of 81 dolphin blow samples coloured according to their ID (individual dolphins). Although not clearly evident in this plot, the mvabund-based analysis showed a significant impact of the factor 'dolphin ID'. Fig. S13. nMDS plot based on Bray-Curtis dissimilarity matrix of 81 dolphin blow samples coloured according to the dolphins' sex. The diagram provides a hint that the mvabund-based analysis showed a significant impact of the factor 'sex' on the microbial communities. Fig. S14. nMDS plot based on Bray-Curtis dissimilarity matrix of 81 dolphin blow samples coloured according to the dolphins' age groups. The diagram provides some evidence that the mvabund-based analysis showed a significant impact of the factor 'age' on the microbial communities. The analysis was based on four age levels: 1: 0-10 years, 2: 11-20 years, 3: 21-30 years, 4: 31-40 years. Fig. S15. Frequency histogram showing the presence of 503 intra-core zOTUs across 11 bottlenose dolphins. Although a large number of intra-core zOTUs is present, only a minority is shared by most dolphins. Fig. S16. Frequency histogram showing the presence of 97 inter-core zOTUs across ten dolphins in week $2,6,11,19,28,37$. More than half of the inter-core zOTUs were only present at one sampling point. Fig. S17. nMDS plot based on Bray-Curtis dissimilarity matrix of 81 dolphin blow samples coloured according to their health status. The mvabund-based analysis did not provide evidence for a general difference between healthy/untreated and sick/treated dolphin. Fig. S18. nMDS plot based on Bray-Curtis dissimilarity matrix of 16 blow samples of dolphins that had received an antimicrobial treatment during the sample collection period. The samples are coloured according to the timing of their collection relative to the timing of treatment ('Before': samples collected before treatment started; 'Directly_after': samples collected within one week after treatment). The mvabund-based analysis provided evidence for a significant difference between the 'Before' and the 'Directly_after' samples. Fig. S19. nMDS plot based on Bray-Curtis dissimilarity matrix of 18 blow samples of dolphins that had received an antimicrobial treatment during the sample collection period. The samples are coloured according to the timing of their collection relative to the timing of treatment ('After': samples collected at least two weeks after treatment started; 'Directly_after': samples collected within one week after treatment). The mvabund-based analysis provided evidence for a significant difference between the 'After' and the 'Directly_after' samples. Fig. S20. This scatterplot shows the temporal dynamics of the inter-core in the studied dolphins from week 2 to 37 . The inter-core was defined as those zOTUs that were present across ten dolphins, randomly selected from our 13 study dolphins, at a specific time point. We picked weeks 2, 6, 11, 19, 28 and 37 as these points in time. Table S1. Shows those 157 zOTUs and their taxonomy that were identified as technical contaminants and subsequently deleted from the dataset of dolphin blow microbiota. Table S2. Alpha diversity parameters of dolphin blow microbiota for each time point over the sampling period of 37 weeks: richness, diversity, Chao1 and ACE species estimators.

\section{Acknowledgements}

We thank the staff veterinarian Dr. David Blyde and the entire dolphin trainer team at Sea World Marine Park Gold Coast Australia for dolphin blow and pool water collection. We also thank all lab members of the Ferrari lab for their support and advice.

\section{Authors' contributions}

T.N., T.T., T.R., B.F. and C.V. contributed to the design of the study. C.V. performed the collection of the data. C.V. performed the analysis of the data. T.N., B.F., T.T., T.R. and C.V. contributed to the interpretation of the results. 
T.N., T.T., T.R. and C.V. contributed to the writing of the manuscript. All authors reviewed and approved of the final version of the manuscript.

\section{Funding}

Sampling equipment and DNA sequencing was funded by a grant of the Scott Foundation awarded to Tracey Rogers. Lab equipment was funded by the Australian Research Council awarded to Belinda Ferrari.

\section{Availability of data and materials}

Sequence data of the dolphin blow, water and technical control samples are available in the NCBI Sequence Read Archive under BioProject accession no PRJNA562386. The code script of the statistical analysis in R studio is available as supplementary material S1

(S1_RCode_Dolphin.blow.manuscript.nb).

\section{Ethics approval and consent to participate}

The sample collection was performed under University of New South Wales (UNSW Sydney) animal care and ethics committee (ACEC) permit no. 16/81A.

\section{Consent for publication}

Not applicable.

\section{Competing interests}

The authors declare that they have no competing interests.

\section{Author details}

${ }^{1}$ Evolution and Ecology Research Centre, School of Biological, Earth and Environmental Sciences, University of New South Wales, Sydney, NSW 2052, Australia. ${ }^{2}$ Queensland Facility for Advanced Bioinformatics, Griffith University, Gold Coast, Southport, QLD 4215, Australia. ${ }^{3}$ School of Biotechnology and Biomolecular Sciences, University of New South Wales, Sydney, NSW 2052, Australia. ${ }^{4}$ Centre for Marine Science and Innovation, School of Biological, Earth and Environmental Sciences, University of New South Wales, Sydney, NSW 2052, Australia.

Received: 9 March 2020 Accepted: 20 December 2020

Published online: 09 January 2021

\section{References}

1. Bik EM, Costello EK, Switzer AD, Callahan BJ, Holmes SP, Wells RS, et al. Marine mammals harbor unique microbiotas shaped by and yet distinct from the sea. Nat Commun. 2016;7:1.

2. Cardona C, Lax S, Larsen P, Stephens B, Hampton-Marcell J, Edwardson CF et al. Environmental sources of bacteria differentially influence hostassociated microbial dynamics. MSystems. 2018;3:e00052-18.

3. Johnson WR, Torralba M, Fair PA, Bossart GD, Nelson KE, Morris PJ. Novel diversity of bacterial communities associated with bottlenose dolphin upper respiratory tracts. Environ Microbiol Rep. 2009:1:555-62.

4. Lima N, Rogers T, Acevedo-Whitehouse K, Brown MV. Temporal stability and species specificity in bacteria associated with the bottlenose dolphins respiratory system. Environ Microbiol Rep. 2012;4:89-96.

5. Nelson TM, Wallen MM, Bunce M, Oskam CL, Lima N, Clayton L, et al. Detecting respiratory bacterial communities of wild dolphins: implications for animal health. Mar Ecol Prog Ser. 2019;622:203-17.

6. Raverty SA, Rhodes LD, Zabek E, Eshghi A, Cameron CE, Hanson MB, et al. Respiratory microbiome of endangered southern resident killer whales and microbiota of surrounding sea surface microlayer in the eastern North Pacific. Sci Rep. 2017;7:1-12.

7. Apprill A, Miller CA, Moore MJ, Durban JW, Fearnbach H, Barrett-Lennard LG. Extensive core microbiome in drone-captured whale blow supports a framework for health monitoring. MSystems. 2017;2:e00119-17.

8. Hunt KE, Moore MJ, Rolland RM, Kellar NM, Hall AJ, Kershaw J, et al. Overcoming the challenges of studying conservation physiology in large whales: a review of available methods. Conserv Physiol. 2013;1:1-24.

9. Fagundes CT, Amaral FA, Vieira AT, Soares AC, Pinho V, Nicoli JR, et al. Transient TLR activation restores inflammatory response and ability to control pulmonary bacterial infection in germfree mice. J Immunol. 2012; 188:1411-20.

10. de Steenhuijsen Piters WA, Sanders EA, Bogaert D. The role of the local microbial ecosystem in respiratory health and disease. Philos Trans R Soc B Biol Sci. 2015;370:20140294
11. Esposito S, Principi N. Impact of nasopharyngeal microbiota on the development of respiratory tract diseases. Eur J Clin Microbiol Infect Dis. 2018;37:1-7

12. Budden KF, Gellatly SL, Wood DL, Cooper MA, Morrison M, Hugenholtz P, et al. Emerging pathogenic links between microbiota and the gut-lung axis. Nat Rev Microbiol. 2017:15:55-63.

13. Dickson RP, Huffnagle GB. The lung microbiome: new principles for respiratory bacteriology in health and disease. PLoS Pathog. 2015;11:e1004923.

14. Venkataraman A, Bassis CM, Beck JM, Young VB, Curtis JL, Huffnagle GB, et al. Application of a neutral community model to assess structuring of the human lung microbiome. MBio. 2015;6:e02284-14.

15. Charlson ES, Bittinger K, Haas AR, Fitzgerald AS, Frank I, Yadav A, et al. Topographical continuity of bacterial populations in the healthy human respiratory tract. Am J Respir Crit Care Med. 2011;184:957-63.

16. Dickson RP, Erb-Downward JR, Falkowski NR, Hunter EM, Ashley SL, Huffnagle GB. The lung microbiota of healthy mice are highly variable, cluster by environment, and reflect variation in baseline lung innate immunity. Am J Respir Crit Care Med. 2018;198:497-508.

17. Bassis CM, Erb-Downward JR, Dickson RP, Freeman CM, Schmidt TM, Young $V B$, et al. Analysis of the upper respiratory tract microbiotas as the source of the lung and gastric microbiotas in healthy individuals. MBio. 2015:e0003715.

18. Morris A, Beck JM, Schloss PD, Campbell TB, Crothers K, Curtis JL, et al Comparison of the respiratory microbiome in healthy nonsmokers and smokers. Am J Respir Crit Care Med. 2013;187:1067-75.

19. Segal LN, Clemente JC, Tsay J-CJ, Koralov SB, Keller BC, Wu BG, et al. Enrichment of the lung microbiome with oral taxa is associated with lung inflammation of a Th17 phenotype. Nat Microbiol. 2016;1:16031.

20. Reidenberg JS, Laitman JT. Position of the larynx in Odontoceti (toothed whales). Anat Rec. 1987:218:98-106.

21. Reidenberg JS, Laitman JT. Anatomy of the hyoid apparatus in odontoceli (toothed whales): specializations of their skeleton and musculature compared with those of terrestrial mammals. Anat Rec. 1994;240:598-624.

22. Reidenberg JS, Laitman JT. Identifying the sound source in mysticetes. Eur Res Cetaceans. 1999;12:259-61.

23. Kooyman GL, Ponganis PJ. The physiological basis of diving to depth: birds and mammals. Annu Rev Physiol. 1998;60:19-32

24. Piscitelli MA, McLellan WA, Rommel SA, Blum JE, Barco SG, Pabst DA. Lung size and thoracic morphology in shallow-and deep-diving cetaceans. J Morphol. 2010:271:654-73.

25. Ridgway SH, Scronce BL, Kanwisher J. Respiration and deep diving in the bottlenose porpoise. Science. 1969:166:1651-4.

26. Bramble DM, Carrier DR. Running and breathing in mammals. Science. 1983; 219:251-6.

27. Schmidt-Nielsen K. Animal physiology: adaptation and environment. Cambridge: Cambridge University Press; 1997.

28. Dickson RP, Erb-Downward JR, Martinez FJ, Huffnagle GB. The microbiome and the respiratory tract. Annu Rev Physiol. 2016;78:481-504.

29. Einarsson GG, Comer DM, Mcllreavey L, Parkhill J, Ennis M, Tunney MM, et al. Community dynamics and the lower airway microbiota in stable chronic obstructive pulmonary disease, smokers and healthy non-smokers. Thorax. 2016;71:795-803.

30. Faner R, Sibila O, Agustí A, Bernasconi E, Chalmers JD, Huffnagle GB, et al. The microbiome in respiratory medicine: current challenges and future perspectives. Eur Respir J. 2017;49:1602086.

31. Segal LN, Clemente JC, Wu BG, Wikoff WR, Gao Z, Li Y, et al. Randomised, double-blind, placebo-controlled trial with azithromycin selects for antiinflammatory microbial metabolites in the emphysematous lung. Thorax. 2017;72:13-22.

32. Slater M, Rivett DW, Williams L, Martin M, Harrison T, Sayers I, et al. The impact of azithromycin therapy on the airway microbiota in asthma. Thorax. 2014:69:673-4.

33. Rogers GB, Bruce KD, Martin ML, Burr LD, Serisier DJ. The effect of long-term macrolide treatment on respiratory microbiota composition in non-cystic fibrosis bronchiectasis: an analysis from the randomised, double-blind placebo-controlled BLESS trial. Lancet Respir Med. 2014:2:988-96.

34. Di Cicco M, Pistello M, Jacinto T, Ragazzo V, Piras M, Freer G, et al. Does lung microbiome play a causal or casual role in asthma? Pediatr Pulmonol. 2018;53:1340-5 
35. Shade A, Handelsman J. Beyond the Venn diagram: the hunt for a core microbiome. Environ Microbiol. 2012;14:4-12.

36. Hernandez-Agreda A, Gates RD, Ainsworth TD. Defining the core microbiome in corals' microbial soup. Trends Microbiol. 2017;25:125-40.

37. Google maps. Google maps. 2019. https://www.google.com/maps/place/ Sea+World/@-27.9584944,153.4250764,155m/data=!3m1!1e3!4m5!3m4!1 s0x6 b910fbcb65bf0db:0xfac5c569854751a0!8m2!3d-27.9572417!4d153.4255161. Accessed 2 Aug 2019.

38. Chao A. Nonparametric estimation of the number of classes in a population Scand J Stat. 1984:11:265-70.

39. Chao A. Estimating the population size for capture-recapture data with unequal catchability. Biometrics. 1987:43:783-91.

40. Chao A, Hwang W-H, Chen YC, Kuo CY. Estimating the number of shared species in two communities. Statistica sinica. 2000;10:227-46.

41. Chao A, Yang MC. Stopping rules and estimation for recapture debugging with unequal failure rates. Biometrika. 1993:80:193-201.

42. Wang YI, Naumann U, Wright ST, Warton DI. mvabund-an R package for model-based analysis of multivariate abundance data. Methods Ecol Evol. 2012;3:471-4.

43. Warton DI, Thibaut L, Wang YA. The PIT-trap_A "model-free" bootstrap procedure for inference about regression models with discrete, multivariate responses. PLoS One. 2017;12:e0181790.

44. McFadden D. Conditional logit analysis of qualitative choice behavior; 1973.

45. Venn-Watson S, Smith CR, Jensen ED. Primary bacterial pathogens in bottlenose dolphins Tursiops truncatus: needles in haystacks of commensal and environmental microbes. Dis Aquat Org. 2008;79:87-93.

46. Venn-Watson S, Daniels $\mathrm{R}$, Smith C. Thirty year retrospective evaluation of pneumonia in a bottlenose dolphin Tursiops truncatus population. Dis Aquat Org. 2012;99:237-42

47. Waltzek TB, Cortés-Hinojosa G, Wellehan JFX Jr, Gray GC. Marine mammal zoonoses: a review of disease manifestations. Zoonoses Public Health. 2012; 59:521-35.

48. Logares R, Deutschmann IM, Junger PC, Giner CR, Krabberød AK, Schmidt TS, et al. Disentangling the mechanisms shaping the surface ocean microbiota. Microbiome. 2020;8:1-17.

49. Teo SM, Mok D, Pham K, Kusel M, Serralha M, Troy N, et al. The infant nasopharyngeal microbiome impacts severity of lower respiratory infection and risk of asthma development. Cell Host Microbe. 2015;17:704-15.

50. Lundberg R, Bahl MI, Licht TR, Toft MF, Hansen AK. Microbiota composition of simultaneously colonized mice housed under either a gnotobiotic isolator or individually ventilated cage regime. Sci Rep. 2017;7:42245

51. Vendl C, Slavich E, Wemheuer B, Nelson T, Ferrari B, Thomas T, et al. Respiratory microbiota of humpback whales may be reduced in diversity and richness the longer they fast. Sci Rep. 2020;10:1-13.

52. Bioinformatics.babraham.ac.uk. FastQC A Quality Control tool for High Throughput Sequence Data. 2019. http://www.bioinformatics.babraham.ac uk/projects/fastqc. Accessed 20 Jan 2019.

53. Edgar RC. UPARSE: highly accurate OTU sequences from microbial amplicon reads. Nat Methods. 2013;10:996-8.

54. Callahan BJ, McMurdie PJ, Holmes SP. Exact sequence variants should replace operational taxonomic units in marker-gene data analysis. ISME J. 2017:11:2639-43

55. Pinheiro J, Bates D, DebRoy S, Sarkar D, Team RC nlme. Linear and nonlinear mixed effects models. R package version. 2013;3:111

56. Seferovic MD, Pace RM, Carroll M, Belfort B, Major AM, Chu DM, et al. Visualization of microbes by 165 in situ hybridization in term and preterm placentas without intraamniotic infection. Am J Obstet Gynecol. 2019;221:146-e1.

57. McMurdie PJ, Holmes S. phyloseq: an R package for reproducible interactive analysis and graphics of microbiome census data. PloS one. 2013:8:e61217.

58. Lindstrom MJ, Bates DM. Nonlinear mixed effects models for repeated measures data. Biometrics. 1990:46:673-87.

59. Crainiceanu CM, Ruppert D. Likelihood ratio tests in linear mixed models with one variance component. J R Stat Soc Ser B (Statistical Methodology). 2004;66:165-85.

60. Brooks ME, Kristensen K, van Benthem KJ, Magnusson A, Berg CW, Nielsen A, et al. glmmTMB balances speed and flexibility among packages for zeroinflated generalized linear mixed modeling. The R journal. 2017;9:378-400.

61. Oksanen J, Blanchet FG, Kindt R, Legendre P, Minchin PR, O'hara RB, et al. Community ecology package. $\mathrm{R}$ package version. 2013:2. Version 2.0

\section{Publisher's Note}

Springer Nature remains neutral with regard to jurisdictional claims in published maps and institutional affiliations.
Ready to submit your research? Choose BMC and benefit from:

- fast, convenient online submission

- thorough peer review by experienced researchers in your field

- rapid publication on acceptance

- support for research data, including large and complex data types

- gold Open Access which fosters wider collaboration and increased citations

- maximum visibility for your research: over $100 \mathrm{M}$ website views per year

At BMC, research is always in progress.

Learn more biomedcentral.com/submissions 